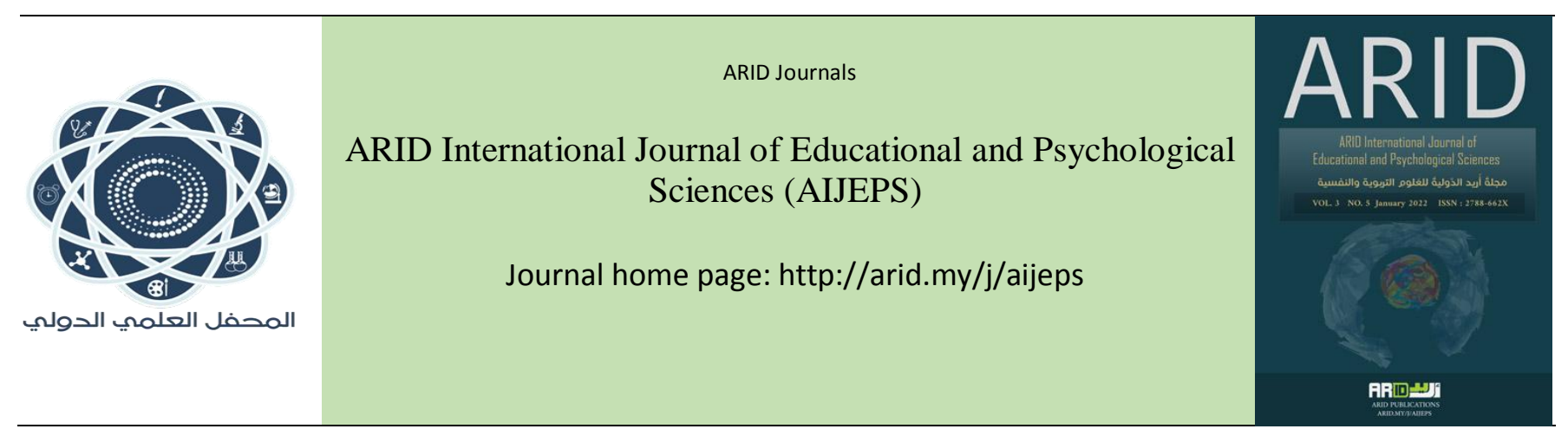

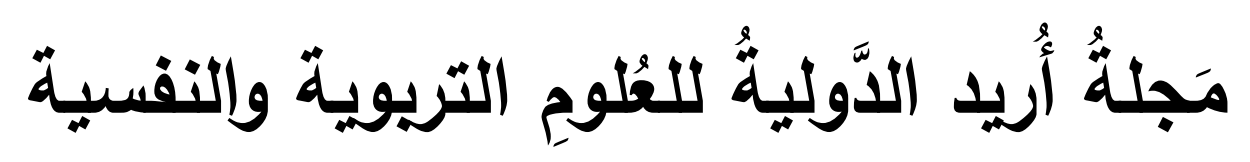 العدد 5 ، المجلد 3 ، كانون الثاني 2022 م
}

\section{Cyber-bullying (bully-victim) Among University Students in Jordan regarding Specialization, GPA, Birth Order, Age, and Gender}

\author{
Aya Subhi Kafineh \\ Mustafa Qaseem Heilat \\ Educational Psychology/ Al- Balqa Applied University, Jordan
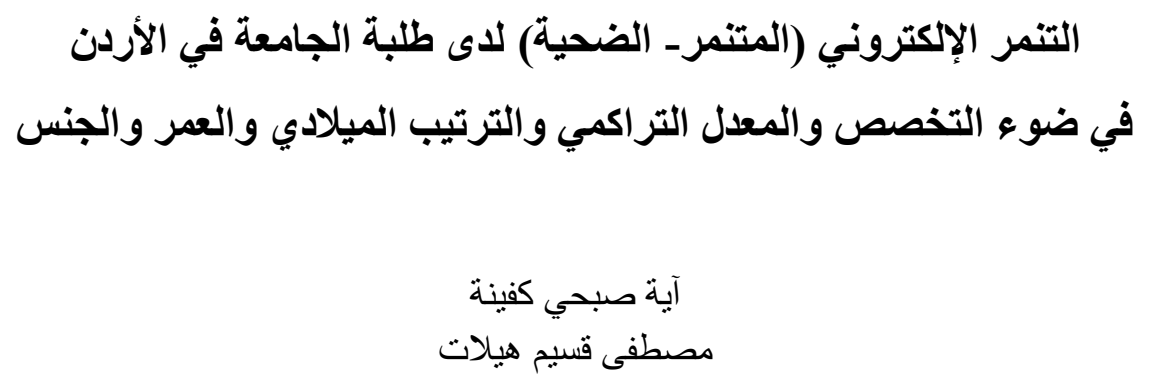 \\ علم النفس التربوي - جامعة البلقاء التطبيقية ـ الأردن




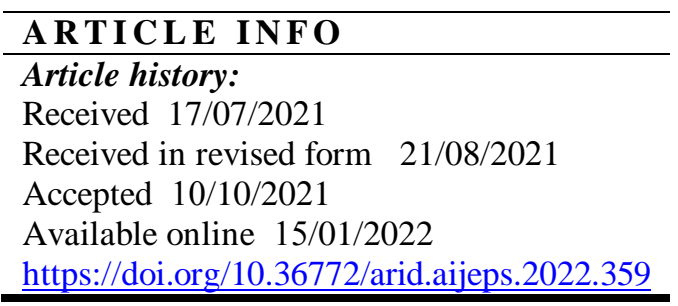

\begin{abstract}
The current study aimed to reveal the cyber-bullying (bully - victim) among university students in Jordan regarding specialization, GPA, birth order, age, and gender. To achieve the objectives of the study, the Cyber-bullying (bully - victim) scale, developed by (Al-Shennawi, 2014), was applied after verifying its psychometric properties. The study sample included 400 male and female students (105 males, 295 females) selected through a stratified random sampling in the academic year of 2019/2020.

According to the bullying, the study results indicated that the Cyber-bullying level (bully) was low. The results also showed statistically significant differences in the overall degree of Cyber-bullying (bully) due to specialization in favor of Science Faculties and gender in favor of males. The results also indicated no statistically significant differences in the overall degree of Cyber-bullying (bully) due to GPA, birth order, and age.

As for Cyber-bullying (the victim), the results showed that the level of the Cyber-bullying (the victim) was low. The results also indicated statistically significant differences in the overall degree of the Cyberbullying (the victim) attributed to birth order in favor of the last son and gender in favor of males. The results also indicated no statistically significant differences in the overall degree of the Cyber-bullying (the victim) attributed GPA, specialization, and age.

The study recommends more care and monitoring for males and their last son, according to their birth order, to protect them from cyberbullying
\end{abstract}

Keywords: Cyber-bullying (bully - victim), University Students, Specialization, GPA, Birth Order, Age, Gender 


\section{الملخص}

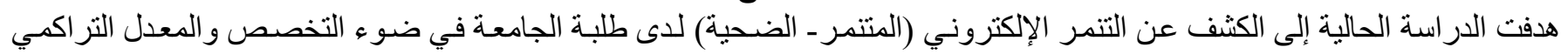

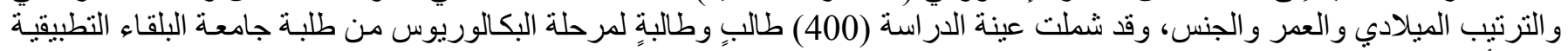

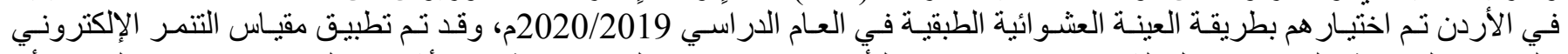

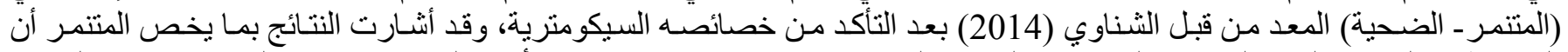

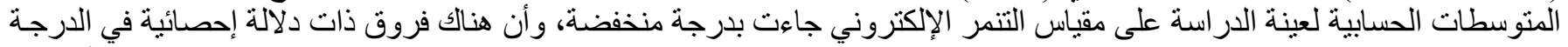

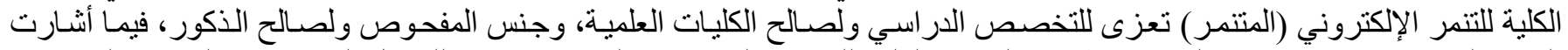

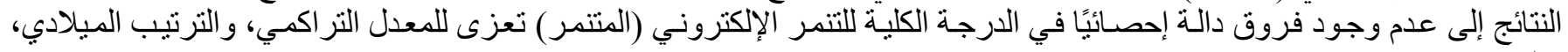

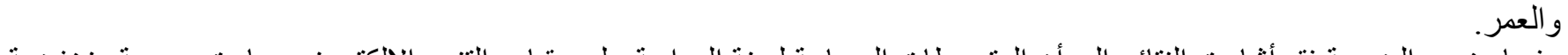

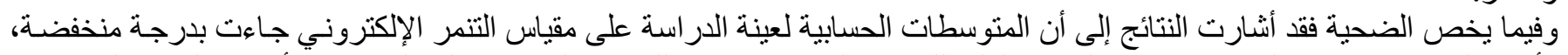

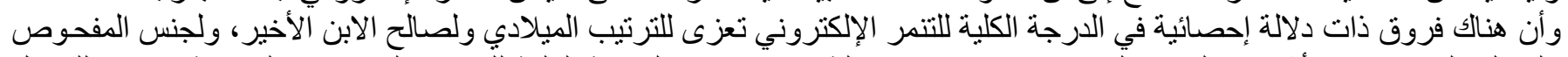

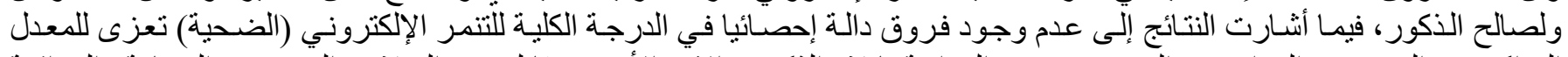

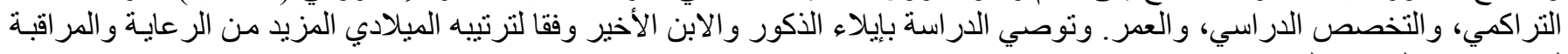
لحمايتهم من التنمر الإلكتروني.

الكلمات المفتاحية: التنمر الإلكتروني، المتنمر، الضحية، التخصص، المعدل التراكمي، الترتيب الميلادي، العمر، الجنس، طلبة الجامعة. 
في عصر العولمة وثورة الاتصالات والمعلومات التي صاحبت الانفجار التقني والمعرفي؛ ظهر وجه جديد للتنمر وهو التنمر الإكتروني (Cyberbullying), البعض اعتبره شكلًا من أشكال التنمر التقليدي أو الاستقواء يحدث بالخفاء تاركا آثار سلبية على الأبناء مع اختلاف أعمار هم، بل له آثاره السلبية على الطالب نفسه وزملائه في شتى الجوانب النفسية والأكاديمية (الصبحيين و القضاة، 2013)، و هو ما استوجب ضرورة توجيه الأنظار وتركيز الاتمام حوله من قبل الباحثين والمربين وذوي الاختصاص، و هو ما استدعى تتاول هذه الظاهرة بالدر اسة والبحث و التي قلما تناولتها الدر اسات و الكتابات والبحوث العربية بشيء من التقصيل بل كانت غالبيتها لدر اسة الظاهرة بشكل عام. إلا أن هناك العديد من الدر اسات الأجنبية التي بحثت في مدى انتشار هذه الظاهرة بين طلبة الجامعات؛ ففي دراسة أمريكية أجر اها فين (Finn, 2004) لسلوك تتمر من آخرين أو مضايقات من خلال رسائل البريد الإكتروني أو الرسائل الفورية، وأن (50\%) من الطلبة تلقوا رسائل غير مرغوب فيها من مو اد إباحية. وفي دراسة أخرى أجريت في جامعة ميدوست Midwestern State University في الولايات المتحدة الأمريكية تبين أن (8.6\%) من الطلاب قد تعرضوا للتنمر الإلكتروني وأن (21.9\%) كانوا متنمرين إلكترونيًا (Mac Donald, 2010). يرى أولويس المشار إلبه في (البهاص، 2012) أن التنمر يشمل أي سلوك عدواني متكرر ومقصود يأتي نتيجة لعدم توازن القوة، كما يهدف إلى إلحاق الأذى بالغير.

يمند التنمر الإلكتروني إلى مناحي الحياة كافة؛ إذ لا يؤدي انقطاع الاتصـال الجسدي المباثر إلى إز الته؛ حيث إنه من الممكن مواجهة التنمر التقليدي من خلال بعض مدونات السلوك والسياسات، أما التنمر الإكتروني فهو بحاجة إلى إجراءات قانونية ذات علاقة بالتنمر الإكتروني، ووضع سياسات وقو انين و أنظمة وتعليمات خاصة به على وجه التحديد)(Buffy \& Dianne, 2009). عرف توكيوناجا (Tokunaga, 2010) التنمر الإلكتروني (Cyberbullying) أنه أب سلوك يتم عبر شبكات الإنترنت أو وسائل الإعلام الإلكترونية أو الرقمية، (Tantawi, 2021). ويمارسه فرد أو جماعة عبر الاتصال المتكرر متضمنا رسائل عدائية أو عدوانية، تهدف إلى إلحاق الضرر والأذى بالآخرين، وقد تكون هوية المتنمر مجهولة أو معروفة للضحية. ومن الخصائص النفسية والثخصية والسلوكية التي يتصف بها من يمارسون التنمر؛ أنهم يسعون إلى إثبات الذات، ولديهم صعوبة في تطبيق القو انين، ويسعون لإظهار فوتهم أمام الآخرين و لا يشعرون مع غير هم (قطامي و الصر ايرة، 2009). ووفقًا لما ذكره كل من كسيو وونج (Xiao \& Wong, 2013) فإن من العوامل المؤثرة على ارتكاب ظاهرة التنمر الإكتروني الخبرة والألفة في استخدام الإنترنت؛ حيث إن الطلبة الذين لايهم المزيد من الخبرة في تشغيل واستخدام الإنترنت وتطبيقاته هم أكثر عرضة 
لأداء أنواع مختلفة من سلوكيات التتمر الإلكتروني؛ كارسال رسائل مضايقة أو تعديل على الصور أو نشر مقاطع فيديو، كما أن القو اعد الاجتماعية Social Norms تؤثر بشكل كبير على احتمال القيام بسلوك التتمر, إضافة إلى الدوافع والتي تعد عاملاً قوياً للقيام بسلوك التتمر لاى طلبة الجامعات الذين يحبون السلطة، والاهتمام، والحاجة للقبول، وقبول الآخرين، لسلوك التنمر (المو افقة الاجتماعية)، كما أن عاملي العمر والجنس من العوامل المهمة التي تنتبأ بسلوك التتمر الإلكتروني؛ حيث تبين أن طلاب الجامعة الكبار بالسن، أقل عرضة للانخراط في سلوك التتمر الإلكتروني، وأن الإناث لديهم ميل أكبر لأداء سلوك التتمر الإلكتروني مقارنة بالذكور. وتثير نتائج دراسة لي (Lee, 2017) إلى وجود ارتباط بين التنمر الإلكتروني وبين التتمر التقليدي والضغوط النفسية من مرحلة الطفولة حتى مرحلة البلوغ، والمترتبات النفسية اللاحقة بين الثباب، حيث أثشارت إلى أن الذكور أكثر ممارسة لسلوك التنمر من الإناث، وفي دراسة أجرتها (Arriaza, 2017) للبحث في أثر التتمر الإلكتروني على الصحة العقلية للإناث؛ خلصت إلى أن هناك دوراً سلبياً للتنتمر الإلكتروني في التأثير على تقدير الذات والاكتئاب والقلق والتفكير الانتحاري/ محاولات الانتحار، والشعور بالوحدة والعزلة، وأوصت الدراسة بضرورة التركيز على دراسة إحساس الإناث لأنهن يستو عبن المشاعر بشكل مختلف عن الذكور. وبينت النتائج المتعلقة بحص الفروق الجنسية في التتمر الإلكتروني الكلي بشكل عام وجود فروق لصالح فئة الذكور Floros et. al 2013; Zhou et. al. 2020) Qudah et. al, El-Shenawy,2014; Barlett,2015; Lee, 2017; Al \&cheng,2014; chan, 2014 Wong, وبثكل عام ما زالت الحاجة ماسة للتحقق التجريبي لفحص الفروق بين الجنسين في سلوك التتمر الإكتروني (المتنمر - الضحية), خاصة في ضوء التضارب والتناقض في نتائج بعض الدراسات السابقة في هذا المجال؛ حيث بينت نتائج بعض الدراسات أن كلا الجنسين من (Hinduja\& Patchin, 2008; الذكور والإناث يمارسون سلوك التتمر أو ينأثرون به بشكل متشابه ولا يوجد فروق بينهما MacDonald and Roberts-Pittman, 2010; Ryan, 2014; Robson\&Witenberg, 2013) وفيما يخص الترتيب الميلادي, فقد كان أدلر أول من تعرض إليه باعتباره أحد العو امل المؤثرة في نمو الثخصية, مؤكدًا عدم وجود التكافؤ. داخل الأسرة بالنسبة للأطفال جميعا؛ مشيرا إلى أن الأطفال الذين يولدون أولا أكثر عرضة لأن يكونو امستقبلا مجرمين ومنحرفين وغالبا ما يشعرون بأهمية القوة وضرورتها في الحياة، بينما يعاني الطفل الأوسط من الضغوط من الجانبين, وعادة ما يطغى عليهم الإحساس بضرورة اللحاق بمن يسبقهم، بينما يميل الطفل الأخير لأن يكون أكثر طموحا وتحديا وافتعالا للمشاكل, وربما كانوا الأكثر لجوءا للهروب (بلتحقالرحمن، 1998). وفي دراسة أجراها كل من هيريرا وزينوك و ويكزوركووسكاو سيهورسكي) Herrera, et al., 2003 من أثر الترتيب الميلادي على سمات الثخصية، طالبوا المشاركين فيها بتقييم الأبناء (البكر و الكنوسطو الأخير) على 11 سمة شخصية؛ و أنثارت النتائج إلى أن البكر هم الأكثر ذكاءً، وتحملا للمسؤولية و إحساسا بالاستقلالية، وأقل عاطفية، وأقل إبداعا، والأطفال الذين ترتيبهم في الأسرة (المتوسط) أكثر حسدا وأقل جرأة وثرثرة، أما الأخير بين إخوتهم فكانوا الأكثر جرأةً، وأكثر هم إبداعًا، وعاطفيَّة، ومنفتحون، 
و أكثر عصيانًا، وغير مسئولين، وحسودين، و أقلهم ثنانًا. و الأبناء البكر آمنوا بأنهم الأكثر قبولًا، كذلك الأمر بالنسبة للأبناء الذين جاءوا في الوسط, أما الأخير بين إخوتهم فقد آمنوا أنهم الأقل قبو لا في الأسرة.

الدراسات السابقة:

قام الحمداني (2012) بدر اسة هدفت إلى الكثف عن مستوى التتمر لدى الأطفال والمر اهقين في ضوء العمر و الجنس والترتيب الو لادي، و الكثف عن دلالة الفرق في التنمر بين تلك الفئات. شملت عينة الدراسة 480 فرداً بو اقع 80 طالبا من طلبة الصف الر ابع الابتدائي، 100 طالب من طلبة الصف السادس الابتدائي، 100 طالب من طلبة الصف الثاني متوسط، و100 طالب من طلبة الصف الرابع الإعدادي، و100 طالب من طلبة الصف السادس الإعدادي ومن كلا الجنسين بالتساوي. أظهرت النتائج أن متوسط الدرجات الكلية للتنمر لدى عينة البحث وفي فئات متغيرات العمر والجنس والترتيب الميلادي كانت أقل من المتوسط الفرضي للمقياس، كما أثارت إلى عدم وجود فرق ذي دلالة في سلوك التنمر بين فئات العمر، ووجود فرق ذي دلالة في سلوك التنمر بين الذكور والإناث ولصالح الذكور، وبين فئات الترتيب الميلادي لصالح الفئات الأكبر. وأجرى كل من بارليت وكوين (Barlett \& Coyne, 2014 ) دراسة سعت إلى تحديد ما إذا كان هناك فروق في التنمر الإلكتروني باختلاف الجنس و العمر وشملت عينة الدراسة 122 طالبًا وطالبة تراوحت أعمار هم بين (10- 15) سنة، وأنشارت النتائج إلى أن الذكور كانو أكثر بقليل تتمرا، وكان العمر قد توسط التأثثر الكلي للتنمر، حيث كن الإناث من عمر المر اهقة المبكرة والمتوسطة أكثر من الذكور تتمر ا بينما كان الذكور أكثر تتمر ا خلال المر اهقة المتأخرة من الإناث. وقامت العباسي (2016) بدراسة هدفت إلى الكثف عن مستوى التتمر لدى تلاميذ المرحلة الابتدائية وطلبة المرحلة المتوسطة باختلاف الجنس و الترتيب الميلادي. شملت العينة (480) طالبا، بواقع (80) طالبا من طلبة الصف الرابع الابتدائي و(100) طالب من طلبة الصف الخامس الابتدائي و(100) طالب من طلبة الصف السادس الابندائي و(200) طالب من طلبة الصف الأول منوسط، أثنارت النتائج إلى أن متوسط الدرجات الكلية للتنمر لدى عينة البحث كان أقل من المتوسط الفرضي للمقياس، كما أثنارت النتائج إلى وجود فرق في سلوك التنمر لصالح الترتيب الميلادي الأول مقارنة بالترتيب الرابع والخامس والسادس، كما تفوق الترتيب الثاني على الترتيب الخامس، وبينت النتائج أيضا أنه كلما زاد الترتيب الميلادي قلت درجة التنمر لديه, ووجود فروق في التنمر الإكتروني تبعا للجنس لصالح

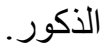

وأجرى كل من المكانين ويونس والحياري (2016) دراسة للكثف عن مستويات التنمر الإلكتروني بالنسبة للطلبة المضطربين سلوكيا و انفعاليا، و الاختلاف في مستويات التنمر الإكتروني تبعا لمتغيري الجنس والعمر؛ شملت العينة 117 طالبا وطالبة من أربع مدارس في مديريـــــة تربية وتعليم الزرقاء للعام الدراسي (2015 /2016) في الأردن، توصلت النتائج إلى أن مستوى التتمر الإكتروني لدى الطلبة 
كان عاليا، كما كانت الفروق في مستويات التنمر الإلكتروني بين الطلبة وفقا لمتغيري الجنس لصالح الطلبة الذكور، ولمتغير العمر لصالح الطلبة الأكبر من 14 سنة.

وقام زيك وآخرون (Zych, et al., 2017) بدر اسة ووصف الكفاءات الاجتماعية والعاطفية للمر اهقين في أسبانيا وفقا لمتغيري العر و الجنس، ومعرفة ما إذا كان مستوى الكفاءات الاجتماعية والعاطفية برتبط بأدوار التتمر والتسلط عبر الإنترنت المختلفة. شملت العينة 2139 مر اهقًا مسجلين في 22 مدرسة. وأظهرت النتائج وجود فروق في الكفاءات الاجتماعية والعاطفية باختلاف الجنس والعمر. كما سجل التنمر والمضايقة عبر الإنترنت والمجرمين من ضحايا الاستبداد درجات منخفضة في الكفاءات الاجتماعية والعاطفية. في حين لم يكن هناك فرق كبير بين الضحايا والطلاب غير المشاركين بالتتمر. و أشتارت النتائج إلى انخفاض الوعي الاجتماعي و السلوك الاجتماعي الإيجابي لدى العينة بغض النظر عن العمر والجنس وكان مرتبطا بشكل مستقل بالجريمة المرتكبة وكونه ضحية التنمر. وقام العنزي (2017) بدراسة هدفت إلى الكثف عن العلاقة بين التنمر الإككتروني عبر مواقع التواصل الاجتماعي وأنماط العنف المدرسي، وقد شملت عينة الدراسة (405) طلاب من طلبة الصف الثالث الثانوي في المدارس الحكومية بمدينة الرياض، و(37) من المرشدين والعاملين في مكاتب الإشراف التربوي، وقد أشارت النتائج إلى وجود علاقة طردية ذات دلالة إحصائية بين أنماط التنمر الإلكتروني عبر مواقع التواصل الاجتماعي وأنماط العنف المدرسي من وجهة نظر الطلبة، كما بينت النتائج أن وضع صورة أو مقطع فيديو للسخرية من الثخص الذي يظهر إضافة لنشر صور لأشخاص دون موافقته من أكثر أنماط التنمر الإلكتروني من وجهة نظر الطلبة، وأوصت الدر اسة بضرورة تثقيف الأبناء باستمر ار حول مشكلة التتمر الإلكتروني وتعزيز الثقة بينهم وبين أبنائهم. وأجرت كفينة (2019) دراسة هدفت إلى الكثف عن القدرة التنبؤية لعوامل الثخصية الخمس الكبرى والذكاء الانفعالي في التنمر الإكتروني لاى طلبة الجامعة، وقد شملت عينة الدراسة 500 طالب وطالبة من طلبة الجامعة الأردنية، وأشارت النتائج إلى تدني مستوى التتمر الإلكتروني لدى عينة الدراسة سواء أكان متتمرًا أم ضحية. كما تبين أن بعد المقبولية كبعد من أبعاد العوامل الثخصية الخمس الكبرى له التأثير الأكبر في التتبؤ في إمكانية أن يكون الفرد متنمرا إلكترونيا، فيما تنبأ بعد العصابية بإمكانية كون الفرد ضحية. كما أنتارت النتائج إلى أن الدرجة الكلية للذكاء الانفعالي تتنبأ في إمكانية أن يكون الفرد متنمرا إلكترونبا ولا تتنبأ بكونه ضحية. وقام شراب وشراب (2019) بدراسة هدفت إلى بناء نموذج نظري مقترح للعلاقة السبيية بين المناخ الأسري للعنف الإكتروني، والأمن النفسي، ومعرفة إذا ما كان المناخ الأسري متغير ا وسيطا في العلاقة بين العنف الإلكتروني والأمن النفسي، وشملت عينة الدراسة (342) طالبًا من الفئة العمرية (14- 16) سنة، أشارت النتائج وجود فروق في العنف الإلكتروني بين الجنسين ولصالح الذكور، فيما لم تشر النتائج إلى وجود فروق في العنف الإكتروني باختلاف الترتيب الميلادي. 


\section{موقع الاراسة الحالية من الاراسات السابقة}

بعد الاطلاع على الدراسات السابقة التي تتاولت التنمر الإلكتروني والتنمر التقليدي تبين أن جميع الدراسات السابقة التي تم التوصل إليها باستثناء در اسة كفينة (2019) شملت عيناتها طلبة مدارس سو اء من المرحلة الأساسية أو الثانوية، وما يميز الدراسة الحالية أن عينتها شملت طلبة الجامعة من كلا الجنسين، إضافة إلى أن التنمر الإكتروني تم بحثه من خلال (المتنمر والضحية) حيث لم يتم ذلك في الدر اسات السابقة باستثناء در اسة كفينة (2019) إلا أن هدف الدر اسة الحالية يختلف بشكل كبير مع هدف دراسة كفينة (2016)، كما تتميز هذه الدراسة بأنها جمعت متغير ات لم تجمعها أي من الدراسات السابقة وهي التنمر الإلكتروني (المتنمر، والضحية) و التخصص و المعدل التر اكمي والترتيب الميلادي و العمر والجنس، وقد استفادت الدر اسة الحالية من الأدب النظري والدراسات السابقة في بناء الإطار النظري للار اسة الحالية, وتحديد أداة الدر اسة التي تم استخدامها، وفي مناقثة النتائج وصياغة التوصيات. مشكلة الار اسة وأسئلتها: لوحظ انتشار ظاهرة التنمر الإلكتروني بين الطلبة في المر احل التعليمية المختلفة, والتي أصبحت ظاهرة واضحة للعيان في المجتمع؛ ذللك لتميز ها بإمكانية التخفي و الغموض للمتتمر و عدم حاجته للمواجهة المباشرة. مما جعل خطورتها ملفتة خصوصًا مع الانفتاح الذي تتسم باه بيئة الويب ومو اقع التواصل الاجتماعي وإمكانية نشر ما يؤذي الضحايا نفسيا واجتماعيا، وربما ماديا وبسرعة فائقة، ولما له من آثار نفسية منباينة على شخص الضحية بل ربما امتد الضرر لينال من حياتهم على المدى البعيد؛ حيث أظهرت العديد من البحوث والدراسات ارتباط التنمر الإلكتروني بالمشاعر الاكتئابية أو القلق وغيرها من الاضطر ابات والمشكلات السلوكية والانفعالية, بالإضافة إلى تأثثيره

السلبي بشكل جلي على تحصيل الطلبة الأكاديمي (Baker \&Tankulu, 2010). كما لوحظ أن اهتمام الدراسات العربية السابقة حول ظاهرة التنمر الإكتروني حسب علم الباحثين نركز على البحث عن مدى انتثار هذه الظاهرة وبناء مقاييس للتنمر الإكتروني، ولم تركز إلى حد ما على فهم حيثيات الظاهرة و إدراك أسبابها أو العو امل الكامنة ور اءها. ولذلك ومع الحاجة الماسة للوقوف على ظاهرة التنمر الإلكتروني وإدر اكها بشكل أكثر عمقاوتفصيلا نظر الخطورتها وآثار ها السلبية على الفرد و المجتمع، جاءت هذه الدراسة لتسهم قدر الإمكان في رفد موضوع التنمر الإلكتروني بشيء من التركيز و العمق في المفهوم وتقديم بعض العو امل التي قد تؤثر عليه. وبناءً على ما سبق سعت الدراسة الحالية إلى محاولة فهم هذه الظاهرة والتعمق بها من خلال البحث في علاقة التنمر الإلكثروني (المتنمر - الضحية), ببعض المتغير ات كالمعدل التر اكمي والتخصص و الترتيب الميلادي و العمر والجنس، وعليه تم تحديد مشكلة الدراسة من خلال أسئلة الدراسة الآتية. 


\section{أهمية الدراسة ومبرراتها:}

الأهمية النظرية، من المؤمل أن تقلم الدراسة الحالية معلومات حول الفروق في ظاهرة التنمر الإكتروني باختلاف بعض المتغيرات, كالمعدل التر اكمي و التخصص والترتيب الميلادي والعمر والجنس والمعدل، الأمر الذي ينعكس على معرفة بعض العوامل ذات العلاقة بظاهرة التنمر الإلكتروني، إضافة إلى تزويد الباحثين بالأبب النظري و الدراسات السابقة بحيث يمكن للباحثين والمهتمين الرجوع إليها و الاستفادة منها، وقد تزيد هذه الدراسة من مستوى الوعي بأهمية ظاهرة التنمر الإلكتروني. الأهمية العملية، من المؤمل أن تسهم هذه الدراسة في تقديم بعض العوامل التي قد يكون لها دور في ظاهرة التتمر الإلكتروني، مما يعين التربويين و الجهات المختصة وأولياء الأمور و المهتمين على اتخاذ الإجراءات اللازمة للحد من هذه الظاهرة, و التقليل من آثار ها السلبية على الفرد و المجتمع، إضافة إلى تقديم توصيات لتصميم برامج وقائية أو إرشادية أو علاجية تقوم على مساعدة ضحايا التتمر الإلكتروني على تجاوز الآثار السلبية الواقعة عليهم جر اء تعرضهم للتنمر الإلكتروني، وذلك للحد من ظاهرة التنمر الإلكتروني بناء على النتائج التي سيتم التوصل إليها، كما أنها عملت على توفير أدوات بحثية مناسبة للبيئة الأردنية يمكن الرجوع إليها و الاستفادة منها. أسئلة الار اسة 1- ما مستوى التنمر الإلكتروني "المتنمر والضحية" لدى عينة الدراسة؟

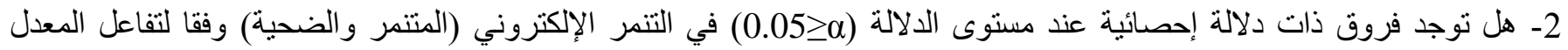
و التخصص؟ 3- هل نوجد فروق ذات دلالة إحصائية عند مستوى الدلالة (0.05ج) في التنمر الإكتروني (المتنمر والضحية) وفقا لتفاعل الترتيب الميلادي و المعدل؟ - n

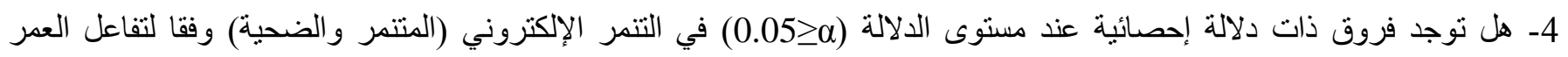
و الجنس؟ أهداف الار اسة: 1- تعرف مستوى التنمر الإلكتروني "المتنمر والضحية" لدى عينة الدراسة. 2- تعرف فيما إذا كان هناك فروق في التنمر الإكتروني "المتنمر والضحية" باختلاف المعدل, والتخصص, و الترنيب الميلادي, و العمر, و الجنس لدى عينة الدر اسة. حدود الار اسة ومحدداتها: ـ الحدود المكاتية: اقتصرت هذه الدر اسة على طلبة جامعة البلقاء التطبيقية/ مركز الجامعة في مدينة السلط/ الأردن. 


$$
\text { ـ الحدود الزمانية: طبقت هذه الدر اسة خلال فترة الفصل الدر اسي الأول من العام 2020/2019م. }
$$

ـ فيما تتمنل المحددات في الأدوات المستخدمة في الدراسة وخصائصها السيكومترية والأطر النظرية التي تم اعتمادها عند بنائها، ممثلة بمقياس التتمر الإكتروني (المتنمر - الضحية)، كما تتمثل المحددات بخصائص عينة الدراسة و إمكانية تعميم النتائج على عينات أخرى ممائلة.

\section{مصطلحات الدراسة وتعريفاتها الإجرائية:}

- التنمر الإكتروني Cyber Bullying: يعرف توكيوناجا (Tokunaga, 2010) التنمر الإلكتروني بأنه أب سلوك يتم عبر شبكات الإنترنت أو وسائل الإعلام الإلكترونية أو الرقمية، ويمارسه فرد أو جماعة عبر الاتصال المتكرر, متضمنًا رسائل عدائية أو عدوانية، تهدف إلى إلحاق الضرر والأذى بالآخرين، سواء أكانت هوية المتنمر مجهولة أو معروفة للضحية، ويعرف إجرائيا في هذه الدراسة بالدرجة التي يحصل عليها أفر اد الدراسة من خلال استجابتهم على مقياس التنمر الإلكتروني (المتنمر - الضحية) الذي أعد من قبل (الثناوي، 2014)، المستخدم في هذه الدر اسة. و ون الجدير بالذكر أن مُطورة المقياس عمدت إلى تقسيم فقرات مقياس التتمر الإكتروني (المتنمر) إلى أربعة أبعاد, وهي (تشويه السمعة و التحرش الجنسي، الإقصاء، والسخرية والتهديد، وانتهاك الخصوصية)، ومقياس (الضحية) إلى خمسة أبعاد وهي (الاستهزاء ونتويه السمعة، والإقصاء، و الإزعاج و انتهاك الخصوصية، والإهانة والتهديد، والتحرش الجنسي) وأوصت معدة المقياس بالتعامل مع المقياس (الضحية) و(المتنمر ) كدرجة كلية؛ وذلك لأن تشبعات الفقرات من خلال التحليل العاملي الاستكثافي قد فسرت نسبة أعلى من التباين على عامل واحد عنها فيما لو تم التعامل مع الأبعاد (المقاييس الفرعية) كل على حدة. و عليه تم في الدراسة الحالية التعامل مع المقياس كدرجة كلية وليس كأبعاد. ـ - الترتيب الميلادي: يقصد به وضع الفرد بين إخوته من حيث ترتيهه الميلادي، وهي الفاصل الزمني بين الفرد وأخيه الأكبر والأصغر سنا. ـ التخصص: هو الكلية التي يلتحق بها الطالب ويتابع در استه العلمية فيها, وقد تم تجميع وتقسيم كليات الجامعة في الدر اسة الحالية إلى

$$
\text { كليات (علمية، و إنسانية). }
$$

ـ المعدل التراكمي: هو النظام الذي تعتمد عليه الجامعات لتصنيف مستوى الطلاب ليجتازوا مو اد دراسية معينة، وقد تم تقسيمه لثلاثة مستويات وفقا لنظام النقاط المعتمد في جامعة البلقاء النطبيقية: (مقبول: 2- 2.49، وجيد: 2.5- 2.99، جيد جدا وممتاز : 3-4) ـ العمر: تم تقسيم العمر لفنتين؛ الفئة الأولى من (18- 20) عامًا، والفئة الثانية من (21- 24) عامًا. 
ـ طلبة الجامعة: هم الطلاب الذين تتر اوح أعمار هم بين (18 - 24) عامًا, ويجلسون على مقاعد الدراسة في جامعة البلقاء التطبيقية من

$$
\text { الفصل الدراسي الأول للعام الجامعي 2019/ 2020م. }
$$

منهج الاراسة: تم إجر اء الدراسة وفقا للمنهج الوصفي الارتباطي لملاءمته لأغر اض الدر اسة الحالية.

$$
\text { عينة الاراسة: }
$$

شملت عينة الدراسة (400) طالب وطالبة من طلاب جامعة البلقاء التطبيقية خلال الفصل الأول من العام الدراسي 2020/2019 تم اختيار هم بالطريقة العشوائية الطبقية، حيث كانت وحدة الاختيار الثعبة الصفية، والجدول ( 1 ) يوضح عينة الدراسة.

\begin{tabular}{|c|c|c|c|c|c|c|c|c|c|}
\hline العدد & العمر & العدد & التخصص & العدد & التراكمي & العدد & الولاديب & العدد & الجنس \\
\hline \multirow[t]{2}{*}{105} & \multirow[t]{2}{*}{$20-18$} & \multirow[t]{2}{*}{191} & \multirow{2}{*}{ كلية } & 67 & مقبول & 119 & الأكبر & 105 & ذكور \\
\hline & & & & 141 & جيد & 222 & الأوسط & 295 & إناث \\
\hline 295 & $24-21$ & 209 & إنسانيات & 192 & متاز & 59 & الأخير & 400 & المجموع \\
\hline 400 & & 400 & & 400 & & 400 & المجموع & & \\
\hline
\end{tabular}
جدول(1): عينة الدراسة وفقا للجنس والمعدل التراكمي والتخصص والترتيب الولادي والعمر

أدوات الدراسة:

لتحقيق أهداف الدراسة تم استخدام مقياس التنمر الإكتروني (المتنمر - الضحية) من إعداد (الثناوي، 2014)، حيث تضمنت بنوده سلوكيات التتمر المختلفة من خلال (الرسائل القصيرة، والبريد الإكتروني، والمراسلة الفورية، وغرف الدردشة، ومواقع التواصل الاجتماعي)، وتندرج في ظل التنمر المباشر (اللفظي، وغير اللفظي، الاجتماعي، الخصوصية) والتنمر غير المباشر (انتحال الثخصية، إرسال بر امج ضارة). وتكون المقياس من (52) فقرة موزعين على مقياسين فرعيين يتكون كل منهما من (26) فقرة، بحيث يمثل أحدهما مقياس المتتمر، و الآخر مقياس الضحية، ويتم الإجابة عن فقرات المقياس من خلال مقياس خماسي يتر اوح من (أبدا= 1: دائما = 5)، يختار المفحوص أحد البدائل المعبرة عن قيامه بسلوكيات التنمر (مقياس المتتمر) أو المعبرة عن مروره بمثل هذه الخبرات خلال الستة أشهر الماضية (مقياس الضحية). صدق المقياس الأصلي وثباته (المتنمر- الضحية): قامت الثناوي (2014) بالتحقق من دلالات الصدق باستخدام التحليل العاملي الاستكشافي من خلال طريقة المكونات الأساسية بدون تحديد عدد العوامل، وتبين أن فقرات مقياس المتتمر قد تشبعت على أربعة أبعاد أو عو امل تفسر 58.28\% من التباين الكلي و هي (تتويه السمعة والتحرش الجنسي، الإقصاء، السخرية و التهديد، انتهاك الخصوصية)، وفيما بتعلق بمقياس الضحية فقد أظهرت النتائج تثبع فقرات المقياس على خمسة أبعاد أو عوامل وتفسر ما يقارب 48.23\% من التباين الكلي, وذللك بعد إعادة التحليل لعدم تثبع العامل السادس وبعد القيام بتدوير المحاور و هي (الاستهزاء وتتويه السمعة، الإقصاء، الإزعاج و انتهاك 
كما استخدمت التحليل العاملي الاستكثافي للتحقق من تشبع فقر ات مقياس التنمر الإكتروني (المتتمر - الضحية) على بعد (عامل) واحد مع تحديد عدد الأبعاد (العوامل) ببعد واحد؛ بهدف التأكد من احتمالية استخراج درجة كلية للمقياس، وأظهرت النتائج تشبع فقرات مقياس المتنمر على بعد واحد بجذر كامن مقداره 11.42 ويفسر هذا البعد 43.95\% من التباين الكلي، وتتحصر قيم تشبعات الفقرات عليه بين (0.36 و 0.78). أما بالنسبة لمقياس الضحية فقد أظهرت النتائج أن فقرات المقياس قد تشبعت على بعد واحد بجذر كامن مقداره 6.71 ويفسر هذا البعد 86.85\% من التباين الكلي، وتتحصر قيم تشبعات الفقرات عليه بين (0.33 و 0.65) مع التنويه إلى أن تشبع الفقرة 9 على هذا البعد كان ضعيفا ومقداره 0.25. بالإضافة إلى احتساب صدق التكوين الفرضي وقد جاءت نتائجه مؤكدة وجود فروق دالة إحصائيا بين كل من الذكور و الإناث, من حيث تورط كل منهما في التتمر الإلكتروني كمتنمر أو ضحية لصالح الذكور. واحتساب الصدق التقاربي والصدق التباعدي, وأظهرت النتائج وجود علاقة إيجابية ذات دلالة إحصائية بين إمكانية لجوء الفرد (الضحية) لسلوك التنمر الإلكتروني فيما بعد. وفيما يتعلق بالثبات فقد تحققت الثناوي (2014) من ثبات المقياس بحساب معامل ألفا كرونباخ، وارتباط الفقرة بالدرجة الكلية بعد استبعاد فقرة ما، والمتوسط، وأخيرا التباين للمقياس في حالة حذف درجة فقرة ما؛ وأثنارت النتائج إلى تقارب القيم في الحالتين بعد حذف فقرة ما بقيم المتوسط وتباين المقياس بعد استبعاد درجة فقرة أخرى، حيث كان تذبذب القيم ضمن مدى صغير جدا, وهو ما يشير إلى تجانس جميع الفقرات في قياس السلوك الذي وضعت لقياسه ولدرجة كبيرة. كما أشارت النتائج إلى أن معاملات الارتباط المصحح بين الفقرة و الدرجة الكلية لأبعاد مقياس المتنمر نراوحت بين (0.40 و 0.77) ولمقياس الضحية تراوحت بين (0.34 و 0.60). وأخبرا فقد نراوحت قيم معاملات ألفا كرونباخ لمقياس المتتمر بين (0.64 و 0.93) ولمقياس الضحية تراوحت بين (0.63 و0.78). دلالات الصدق والثبات للمقياس في الدراسة الحالية (المتنمر - الضحية): تم التأكد من صدق المقياس في هذه الدر اسة كما يلي:

أولاـ صدق المحكمين: تم عرض مقياس التنمر الإلكتروني على (8) محكمين من المتخصصين، وتم إجر اء بعض التعديلات البسيطة في ضوء الملاحظات. ثانيا- صدق الاتساق الداخلي بعد إجر اء التعديلات التي أشار إليها المحكمون على العينة الاستطلاعية نم تطبيق المقياس على (86) طالبا وطالبة تم اختبار هم بالطريقة العشوائية الطبقية، وتم إيجاد معاملات الارتباط بين الفقر ات و الدرجة الكلية للمقياس، ودلت النتائج على أن جميع فقرات المقياس دالة إحصائيا عند مستوى الدلالة ( 2 ( 0.00 )، وقد نراوحت معاملات الارتباط بين الفقرات و الدرجة الكلية لمقياس (المتتمر) (48.93.)، فيما تراوحت معاملات الارتباط بين الفقرات والدرجة الكلية لمقياس (الضحية) (35.- 75.) 
وقد تم حساب الثبات لمقياس التنمر الإكتروني (المتنمر) بحساب معامل كرونباخ ألفا Cronbach - Alpha؛ وقد بلغت قيمة معامل ثبات المقياس ( 0.958)، و(الضحية) ( 0.94). إجراءات تطبيق الدراسة: تم اتباع الخطوات و الإجر اءات التالية لغرض تطبيق الدراسة: ـ التحقق من الصدق و الثبات لمقياس التتمر الإلكتروني، بتطبيقه على عينة استطلاعية من مجتمع الدراسة. - تم تطبيق المقياس من خلال طريقتين: حيث تم توزيع نسخة إلكترونية للمقياس تكون الإجابة عنها من خلال رابط إلكتروني على شعب بعينها تم اختيار ها عشو ائيًا، فيما تمثلت الطريقة الثانية بتوزيع نسخ ورقية لمن كان برغب بتعبئتها ورقيا في ذات الثعب التي تم التوزيع بها إلكترونيًا. - ـ تم تفريغ البيانات وإجراء المعالجات الإحصائية اللازمة باستخدام برنامج الرزم الإحصائية للعلوم الاجتماعية SPSS للحصول على النتائج. - متغيرات الاراسة - التتمر الإكتروني بثقيه (المتتمر - والضحية)، والمعدل التراكمي (مقبول، جيد، ممتاز)، والتخصص (كليات علمية، وكليات إنسانية)، و الترتيب الميلادي (الأكبر، والأوسط، والأخير)، و العمر (18 - 20)، و(21- 24)، والجنس (ذكور ، وإناث).

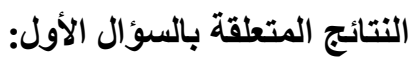
ما مستوى التنمر الإلكتروني "المتنمر والضحية" لاى عينة الاراسة؟ تم حساب المنوسطات الحسابية والانحر افات المعيارية لللرجة الكلية للتنمر الإلكتروني "المتنمر والضحية" كما هو موضح في الجدول (

جدول(2): المتوسطات الحسابية والاتحرافات المعيارية للارجة الكلية لمقياس التنمر الإكتروني (المتنمر والضحية)

\begin{tabular}{|c|c|c|c|}
\hline الدرجة & الانحراف المعياري & المتوسط الحسابي & 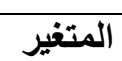 \\
\hline منذفضة & .28240 & 1.1943 & المتنمر \\
\hline منخفضة & .37983 & 1.2638 & الضحية \\
\hline
\end{tabular}

يتضح من الجدول ( 2 ) أن المتوسطات الحسابية للتنمر الإلكتروني (المتنمر والضحية) جاءت بدرجة منخفضة؛ مما يشير إلى تدني مستوى التتمر الإكتروني من جهة المتنمر والضحية، وذلك وفقا لمعيار الحكم المعتمد في الدراسة الحالية. ويمكن تفسير هذه النتيجة بالنظر إلى طبيعة المجتمع الأردني المحافظ بالإضافة إلى مدى حساسية موضوع التتمر الإلكتروني سواء كان متتمرا أو ضحية؛ إذ يبدو أن الاعتراف بالقيام بهذا السلوك أو التعرض له ليس بالأمر السهل و هو ما قد يحول دون اعتراف الطلبة بحقيقة قيامهم أو تعرضهم للتنمر الإلكتروني. و اتفقت هذه النتيجة مع دراسة كفينة (2019). 


\section{جدول(3): معايير الحكم على درجة المتوسطات الحسابية}

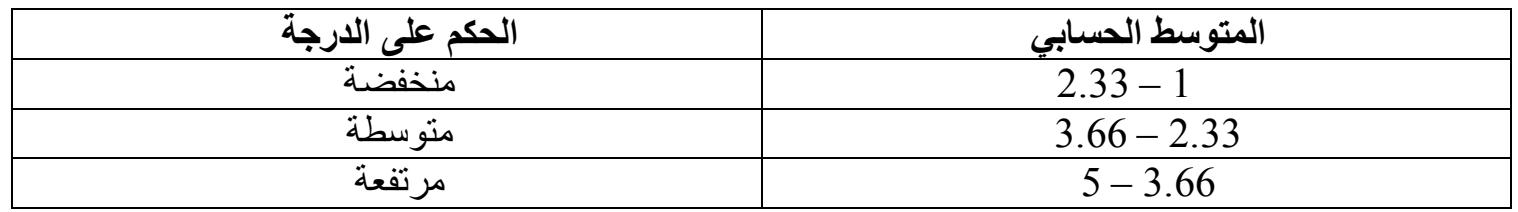

النتائج المتعلقة بالسؤال الثاني:

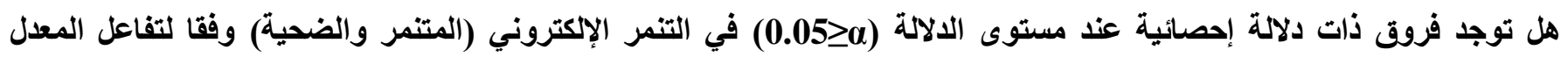
والتخصص؟

أولا: فيما يتعلق بالتنمر الإكتروني (المتنمر)

جدول(4): المتوسطات الحسابية والانحرافات المعيارية للارجة الكلية لمقياس التنمر الإكتروني "المتنمر" وفقا لتفاعل المعل والتخصص

\begin{tabular}{|c|c|c|c|c|c|}
\hline العدد & الانحراف المعياري & المتوسط الحسابي & التخصص & المعدل & المتغير \\
\hline 36 & .37085 & 1.3077 & كليات علمية & \multirow[t]{3}{*}{ مقبول } & \multirow{12}{*}{ الإلإلكترة الكتية } \\
\hline 31 & .25120 & 1.1737 & كليات إنسانية & & \\
\hline 67 & .32580 & 1.2457 & Total & & \\
\hline 62 & .34874 & 1.2258 & كليات علمية & \multirow[t]{3}{*}{ جيد } & \\
\hline 79 & .19058 & 1.1383 & كليات إنسانية & & \\
\hline 141 & .27409 & 1.1768 & Total & & \\
\hline 93 & .33629 & 1.2213 & كليات علمية & \multirow[t]{3}{*}{ مثتاز } & \\
\hline 99 & .18850 & 1.1593 & كليات إنسانية & & \\
\hline 192 & .27142 & 1.1893 & Total & & \\
\hline 191 & .34676 & 1.2390 & كليات علمية & \multirow[t]{3}{*}{ Total } & \\
\hline 209 & .19907 & 1.1535 & كليات إنسانية & & \\
\hline 400 & .28240 & 1.1943 & Total & & \\
\hline
\end{tabular}

يتضح من الجدول أعلاه وجود فروق ظاهرية بين المتوسطات الحسابية بين فئات المعدل التر اكمي والتخصص حسب الكليات، وللكثف عن الفروق الإحصائية فقد تم إجراء تحليل التباين الثنائي، كما هو في الجدول (5). 
جدول(5): تحليل التباين الثنائي Way ANOVA -2 للكثف عن الفروق الدالة إحصائيا بين المعل والتخصص و التفاعل بينهما

\begin{tabular}{|c|c|c|c|c|c|}
\hline الإحصائية & قيمة & المربعات & الحرجية & المربعوات & مصادر التباين \\
\hline .346 & 1.063 & .083 & 2 & .166 & المعدل \\
\hline .002 & 9.361 & .733 & 1 & .733 & التخصص \\
\hline .660 & .417 & .033 & 2 & .065 & المعدل * التخصص \\
\hline & & .078 & 394 & 30.845 & الخطأ \\
\hline & & & 400 & 602.386 & المجموع \\
\hline
\end{tabular}

يتضح من الجدول (5) عدم وجود فروق دالة إحصائيا في الدرجة الكلية للتنمر الإكتروني (المتنمر) تعزى للمعدل التراكمي، وللتفاعل بين المعدل التراكمي والتخصص، فيما أشارت النتائج إلى وجود فروق ذات دلالة إحصائية في الدرجة الكلية لمقياس التنمر الإكتروني (المتنمر ) نعزى للتخصص الدر اسي ولصالح الكليات العلمية. يمكن تفسير هذه النتيجة بالنظر إلى طبيعة طلبة التخصصات العلمية الذين تتطلب تخصصاتهم أن يكونوا أكثر إتقانا وألفة وخبرة في استخدام الإنترنت والأجهزة الإلكترونية؛ حيث إن الطلبة الذين لديهم المزيد من الخبرة في تشغيل واستخدام الإنترنت وتطبيقاته, هم أكثر عرضة لأداء أنواع مختلفة من سلوكيات التنمر الإكتروني (Xiao \& Wong, 2013) كما أن تعرضهم للكثير من الضغوط على المستوى الدر اسي و النفسي؛ قد يدفعهم لتفريغ هذه الضغوط بأساليب خاطئة من خلال التنمر على الغير.

بينما لم يؤثر المعدل التراكمي على التنمر الإلكتروني كسلوك؛ ربما لأن المعدل التراكمي لا يؤثر على شخصية الطالب الجامعي وسلوكياته. ثاتيا: فيما يتعلق بالتنمر الإكتروني (الضحية) جدول(6): المتوسطات الحسابية والانحرافات المعيارية للارجة الكلية لمقياس التنمر الإكتروني "الضحية" وفقا لتفاعل المعل و التخصص

\begin{tabular}{|c|c|c|c|c|c|}
\hline العدد & الانحر اف المعياري & المتوسط الحسابي & التخصص & المعدل & المتغير \\
\hline 36 & .55076 & 1.3269 & كليات علمية & \multirow[t]{3}{*}{ مقبول } & \multirow{12}{*}{ الإلكترجة الكنية } \\
\hline 31 & .41477 & 1.2767 & كليات إنسانية & & \\
\hline 67 & 48959 & 1.3037 & المجموع & & \\
\hline 62 & .38069 & 1.2829 & كليات علمية & \multirow[t]{3}{*}{ جيد } & \\
\hline 79 & .35871 & 1.2074 & كليات إنسانية & & \\
\hline 141 & .36912 & 1.2406 & المجموع & & \\
\hline 93 & .36853 & 1.2849 & كليات علمية & \multirow[t]{3}{*}{ ميتاز } & \\
\hline 99 & .31837 & 1.2502 & كليات إنسانية & & \\
\hline 192 & .34311 & 1.2670 & المجموع & & \\
\hline 191 & .41043 & 1.2922 & كليات علمية & \multirow[t]{3}{*}{ |المجموع } & \\
\hline 209 & .34853 & 1.2379 & كليات إنسانية & & \\
\hline 400 & .37983 & 1.2638 & المجموع & & \\
\hline
\end{tabular}


يتضح من الجدول أعلاه وجود فروق ظاهرية بين المتوسطات الحسابية بين فئات المعدل التراكمي والتخصص وفقا للكليات،

وللكثثف عن الفروق الإحصائية فقد تم إجراء تحليل التباين الثنائي، كما هو موضح في الجدول (7).

جدول(7): تحليل التباين الثنائي 2- Way ANOVA للكثف عن الفروق الدالة إحصائيا بين المعل و التخصص و التفاعل بينهما

\begin{tabular}{|c|c|c|c|c|c|}
\hline الإحصائية & قيمة & المتوبعات & لدرية & المزبعوع & مصادر التباين \\
\hline .604 & .505 & .073 & 2 & .146 & المعدل \\
\hline .204 & 1.621 & .235 & 1 & .235 & التخصص \\
\hline .891 & .115 & .017 & 2 & .033 & المعدل * التخصص \\
\hline & & .145 & 394 & 57.083 & الخطاً \\
\hline & & & 400 & 696.488 & المجموع \\
\hline
\end{tabular}

يتضح من الجدول (7) عدم وجود فروق دالة إحصائيا عند مستوى الدلالة (a 20.05) في الدرجة الكلية للتنمر الإلكتروني (الضحية) تعزى للمعدل التر اكمي، والتخصص الدراسي، وللتفاعل بين المعدل التراكمي و التخصص. يعتقد الباحثان أن حساسية تعرض الفرد للتتمر الإلكتروني قد يحول دون الاعتر اف به. النتائج المتعلقة بالسؤال الثالث

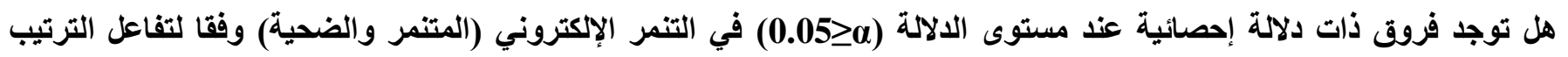
الميلادي والمعدل؟

أولا: فيما يتعلق بالتنمر الإكتروني (المتنمر)

جدول(8): المتوسطات الحسابية والانحرافات المعيارية للارجة الكلية لمقياس التنمر الإكتروني "المتنمر" وفقا لتفاعل الترتيب الميلادي والمعدل

\begin{tabular}{|c|c|c|c|c|c|}
\hline العدد & الانحراف المعياري & الحستبي & المعدل & الترثيب الميب & المتغير \\
\hline 19 & .29090 & 1.2591 & مقبول & \multirow[t]{4}{*}{ الأكبر } & \multirow{14}{*}{ الالكلية للتنمر } \\
\hline 38 & .30981 & 1.2338 & جيد & & \\
\hline 62 & .22635 & 1.1650 & ممتاز & & \\
\hline 119 & .26657 & 1.2020 & المجموع & & \\
\hline 34 & .36924 & 1.2568 & مقبول & \multirow[t]{4}{*}{ الأوسط } & \\
\hline 92 & .26754 & 1.1618 & جيد & & \\
\hline 96 & .31936 & 1.2316 & ممتاز & & \\
\hline 222 & .30849 & 1.2065 & المجموع & & \\
\hline 14 & .26994 & 1.2005 & مقبول & \multirow[t]{4}{*}{ الأخير } & \\
\hline 11 & .15867 & 1.1049 & جيد & & \\
\hline 34 & .16110 & 1.1143 & ممتاز & & \\
\hline 59 & .19209 & 1.1330 & المجموع & & \\
\hline 67 & .32580 & 1.2457 & مقبول & \multirow[t]{2}{*}{ المجموع } & \\
\hline 141 & .27409 & 1.1768 & جيد & & \\
\hline
\end{tabular}




\begin{tabular}{|l|l|l|l|l|l|}
\hline 192 & .27142 & 1.1893 & & \\
\hline 400 & .28240 & 1.1943 & sمتاز & & \\
\hline
\end{tabular}

يتضح من الجدول أعلاه وجود فروق ظاهرية بين المتوسطات الحسابية بين فئات الترتيب الميلادي والمعدل التراكمي، وللكثف عن الفروق الإحصائية فقد تم إجراء تحليل التباين الثنائي، كما هو موضح في الجدول (9). جدول(9): تحليل التباين الثنائي Way ANOVA -2 للكثف عن الفروق الدالة إحصائيا بين الترتيب الميلادي والمعدل والتفاعل بينهما

\begin{tabular}{|c|c|c|c|c|c|}
\hline الإحصائية & قيمة & المربعات & لحرية & المربعاث & مصادر التباين \\
\hline .218 & 1.530 & .121 & 2 & .242 & الترتيب الميلادي \\
\hline .240 & 1.434 & .114 & 2 & .227 & المعدل \\
\hline \multirow[t]{3}{*}{.415} & .985 & .078 & 4 & .312 & الترتيب الميلادي * المعدل \\
\hline & & .079 & 391 & 30.957 & الخطأ \\
\hline & & & 400 & 602.386 & المجموع \\
\hline
\end{tabular}

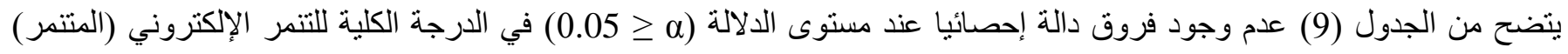
تعزى للترتيب الميلادي، و المعدل التر اكمي، وللتفاعل بين الترتيب الميلادي و المعدل التر اكمي. من الممكن تفسير هذه النتيجة بالرجوع إلى طبيعة أفراد عينة الدراسة كثباب جامعي يتسم بالوعي والإدر الك الذي يحول دون قيامهم بمثل هذا السلوك السلبي، بالإضافة إلى طبيعة المجتمع الأردني المحافظ. تعارضت هذه النتيجة مع در اسة الحمداني (2012) من جهة الترتيب الميلادي؛ إذ كان هناك فروق ذات دلالة لصالح الابن الأكبر مع ضرورة الانتباه لاختلاف عينة الدراسة الحالية عن عينات الدراسات الأخرى من حيث إنها تناولت طلبة الجامعة. ومع دراسة العباسي (2016) التي أنشارت نتيجتها إلى وجود فروق في التنمر الإلكتروني تعزى للترتيب الميلادي، وبينت النتائج أيضا أنه كلما زاد الترتيب الميلادي قلت درجة التنمر. ثانيا: فيما يتعلق بالتنمر الإكتروني (الضحية) جدول(10): المتوسطات الحسابية والانحر افات المعيارية للارجة الكلية لمقياس التنمر الإكتروني "الضحية" وفقا لتفاعل الترتيب الميلادي والمعدل

\begin{tabular}{|c|c|c|c|c|c|}
\hline العدد & الالمعرافي & الحستبي & المعدل & التريلاديب & المتغير \\
\hline 19 & .67222 & 1.4372 & مقبول & \multirow[t]{4}{*}{ الأكبر . } & \multirow{8}{*}{ الإلكترونية الكلية للتنمر } \\
\hline 38 & .52103 & 1.3462 & جيد & & \\
\hline 62 & .33513 & 1.2599 & ممتاز & & \\
\hline 119 & .46521 & 1.3158 & المجمو ع & & \\
\hline 34 & .41814 & 1.2862 & مقبول & \multirow[t]{4}{*}{ الأوسط } & \\
\hline 92 & .29707 & 1.2115 & جيد & & \\
\hline 96 & .35824 & 1.2909 & ممتاز & & \\
\hline 222 & .34511 & 1.2573 & المجموع & & \\
\hline
\end{tabular}




\begin{tabular}{|c|c|c|c|c|}
\hline 14 & .31588 & 1.1648 & مقبول & \multirow[t]{4}{*}{ الأخير } \\
\hline 11 & .18321 & 1.1189 & جيد & \\
\hline 34 & .31549 & 1.2127 & ممتاز & \\
\hline 59 & .29353 & 1.1838 & المجموع & \\
\hline 67 & .48959 & 1.3037 & مقبول & \multirow[t]{4}{*}{ المجموع } \\
\hline 141 & .36912 & 1.2406 & جيد & \\
\hline 192 & .34311 & 1.2670 & ممتاز & \\
\hline 400 & .37983 & 1.2638 & المجموع & \\
\hline
\end{tabular}

يتضح من الجدول أعلاه وجود فروق ظاهرية بين المتوسطات الحسابية بين فئات الترتيب الميلادي والمعدل التراكمي، وللكثف عن الفروق الإحصائية فقد تم إجر اء تحليل التباين الثنائي، كما هو موضح في الجدول (11). جلول(11): تحليل التباين الثنائي 2-Way ANOVA للكثف عن الفروق الدالة إحصائيا بين الترتيب الميلادي والمعدل والتفاعل

\begin{tabular}{|c|c|c|c|c|c|}
\hline الإحصائية & قيمة & المربعات & الحرية & المزبعوع & مصادر التباين \\
\hline .023 & 3.810 & .545 & 2 & 1.090 & الترتيب الميلادي \\
\hline .572 & .559 & .080 & 2 & .160 & المعدل \\
\hline .321 & 1.175 & .168 & 4 & .672 & الترتيب الميلادي * المعدل \\
\hline & & .143 & 391 & 55.939 & الخطأ \\
\hline & & & 400 & 696.488 & المجموع \\
\hline
\end{tabular}

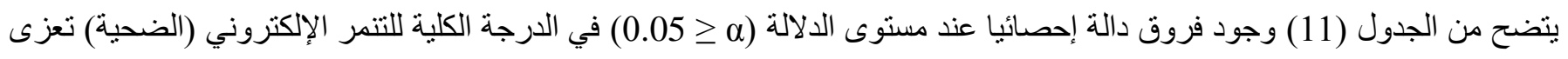
للترتيب الميلادي، فيما أنشارت النتائج إلى عدم وجود فروق ذات دلالة إحصائية في الدرجة الكلية لمقياس التنمر الإلكتروني (الضحية) تعزى للمعدل التر اكمي، وللتفاعل بين الترتيب الميلادي و المعدل التر اكمي. ووفقا لاختبار LSD للمقارنات البعدية لمعرفة مصدر الفروق في الترتيب الميلادي, تبين أن الفرق بين الولا الأكبر والأخير في الترتيب الميلادي دال إحصائيا لصالح الابن الأخير (1319.) عند مستوى الدلالة (0.05). يمكن تفسير هذه النتيجة بالرجوع إلى السمات التي يتسم بها الطفل الأخيركما ذكر (عبدالرحمن، 1998) أن الطفل الأخير يميل لأن يكون أكثر طموحا وتحديا وافتعالا للمشاكل, وربما كان الأكثر لجوءا للهروب. وفي دراسة أجراها كل من هيرير اوزينوك و ويكزوركووسكاو سيهورسكي) أشنارت النتائج إلى أن الطفل الأخير بين إخوته يكون أكثر جرأةً، و أكثر هم إبداعًا، و عاطفيَّة، ومنفتحًا، وأكثر عصيانًا، وغير مسئول، وحسودا، و أقلهم ثبانًا. ويؤمن أنه الأقل قبولًا في الأسرة. وهو ما عرضه ليكون أكثر وقوعا كضحية للتنمر الإلكتروني نظرًا لكونه أكثر انفتاحا على الآخرين وجر أة وافتعالا للمشاكل, إذ ربما سعى أحدهم للانتقام منه عبر الثبكات 
النتائج المتعلقة بالسؤال الرابع

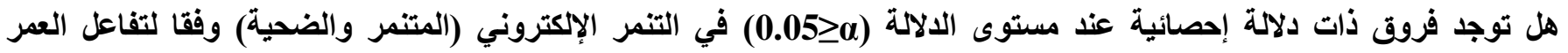
والجنس؟ أولا: فيما يتعلق بالتنمر الإكتروني (المتنمر) جدول(12): المتوسطات الحسابية والانحرافات المعيارية للارجة الكلية لمقياس التنمر الإكتروني "المتنمر" وفقا لتفاعل العمر والجنس

\begin{tabular}{|c|c|c|c|c|c|}
\hline العدد & الانحراف المعياري & المتوسط الحسابي & العمر & الجنس & المتغير \\
\hline 60 & .34434 & 1.2686 & $18-20$ & \multirow[t]{3}{*}{ ذكر } & \multirow{9}{*}{ اللالكلية الإلكتر } \\
\hline 45 & .39111 & 1.3547 & $21-24$ & & \\
\hline 105 & .36581 & 1.3055 & المجموع & & \\
\hline 138 & .25202 & 1.1508 & $18-20$ & \multirow[t]{3}{*}{ أنثى } & \\
\hline 157 & .21835 & 1.1583 & $21-24$ & & \\
\hline 295 & .23433 & 1.1548 & المجموع & & \\
\hline 198 & .28745 & 1.1865 & $18-20$ & \multirow[t]{3}{*}{ المجموع } & \\
\hline 202 & .27786 & 1.2020 & $21-24$ & & \\
\hline 400 & .28240 & 1.1943 & المجموع & & \\
\hline
\end{tabular}

يتضح من الجدول أعلاه وجود فروق ظاهرية بين المنوسطات الحسابية بين فئات العمر والجنس، وللكثف عن الفروق الإحصائية فقد نم إجر اء تحليل التباين الثنائي، كما هو موضح في الجدول (13).

جدول(13): تحليل التباين الثنائي 2- Way ANOVA للكشف عن الفروق الدالة إحصائيا بين العمر والجنس والتفاعل بينهما

\begin{tabular}{|c|c|c|c|c|c|}
\hline الإحصائية الالاية & قيمة & المربعات & الحرية درجات & المربعوع & مصادر التباين \\
\hline .000 & 24.94 & 1.881 & 1 & 1.881 & الجنس \\
\hline .138 & 2.212 & .167 & 1 & .167 & العمر \\
\hline .212 & 1.562 & .118 & 1 & .118 & الجنس * العمر \\
\hline & & .075 & 396 & 29.865 & الخطأ \\
\hline & & & 400 & 602.386 & المجموع \\
\hline
\end{tabular}

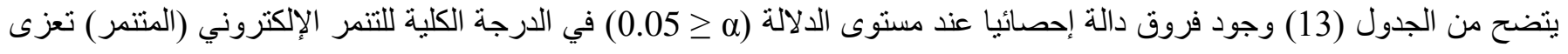
لجنس المفحوص، ولصالح الذكور، حيث بلغت قيمة ف (24.94) عند مستوى الدلالة (000.)، فيما أشارت النتائج إلى عدم وجود فروق ذات دلالة إحصائية في الدرجة الكلية لمقياس التنمر الإلكتروني (المتتمر) تعزى للعمر والتفاعل بين الجنس و العمر. اتفقت هذه النتيجة مع دراسة الحمداني (2012) من حيث عدم وجود فروق دالة في التنمر الإلكتروني (المتنمر) تعزى للعمر، ووجود فروق تعزى لمتغير الجنس ولصالح الذكور, وكذلك الأمر بالنسبة لدراسة العباسي (2016)، ومع دراسة بارليت وكوين( \&arlett من حيث وجود فروق تعزى لمتغير الجنس ولصالح الذكوربينما اختلفت معها من حبث العمر ؛ إذ أثبتت الأخبرة وجود 
فروق قليلة في التنمر الإلكتروني تعزى للعمر مع ضرورة الأخذ بعين الاعتبار أن الدراسة الحالية شملت طلبة جامعة وليس طلبة مدارس. بينما اختلفت مع نتيجة دراسة كل من كسيو وونج Xiao (\& Wong, 2013) التي أشنارت نتائجها إلى وجود فروق في التتمر الإلكتروني تعزى للإناث. ومن المكن تفسير هذه النتيجة بالنظر إلى طبيعة المجتمع الأردني الدحافظ الذي يعطي الذكور مساحة أكبر من الحرية على وسائل التواصل الاجتماعي وشبكات الإنترنت, مما يتيح لهم فرص القيام بسلوك التتمر الإكتروني بشكل أكبر من الإناث، وأن الذكور أكثر جرأة من الإناث باعتبار المجتمعات الثرقية مجتمعات ذكورية. ثانيا: فيما يتطق بالتنمر الإكتروني (الضحية) جدول(14): المتوسطات الحسابية والانحرافات المعيارية للارجة الكلية لمقياس التنمر الإكتروني "الضحية" وفقا لتفاعل العمر والجنس

\begin{tabular}{|c|c|c|c|c|c|}
\hline العدد & الانحراف المعياري & المتوسط الحسابي & العمر - (العز & الجنس & المتغير \\
\hline 60 & .43486 & 1.3378 & $18-20$ & \multirow[t]{3}{*}{ ذكر } & \multirow{9}{*}{ الالضكتربة اللنية } \\
\hline 45 & .52918 & 1.4564 & $21-24$ & & \\
\hline 105 & .47878 & 1.3886 & المجموع & & \\
\hline 138 & .24935 & 1.2099 & $18-20$ & \multirow[t]{3}{*}{ أنثى } & \\
\hline 157 & .38369 & 1.2278 & $21-24$ & & \\
\hline 295 & .32737 & 1.2194 & المجموع & & \\
\hline 198 & .32148 & 1.2486 & $18-20$ & \multirow[t]{3}{*}{ المجموع } & \\
\hline 202 & .42971 & 1.2788 & $21-24$ & & \\
\hline 400 & .37983 & 1.2638 & المجموع & & \\
\hline
\end{tabular}

يتضح من الجدول أعلاه وجود فروق ظاهرية بين المتوسطات الحسابية لاستجابات عينة الدراسة على مقياس التنمر الإلكتروني (الضحية) بين فئات العمر والجنس، وللكثف عن الفروق الإحصائية فقد نم إجراء تحليل التباين الثنائي، كما هو موضح في الجدول (15). جدول(15): تحليل التباين الثنائي 2- Way ANOVA للكثف عن الفروق الدالة إحصائيا بين العمر والجنس و التفاعل بينهما

\begin{tabular}{|c|c|c|c|c|c|}
\hline الإحصائية & قيمة & متوسط المربعات & لدرجية & مجموع المربعات & مصادر التباين \\
\hline .000 & 17.44 & 2.421 & 1 & 2.421 & الجنس \\
\hline .110 & 2.559 & .355 & 1 & .355 & العمر \\
\hline .239 & 1.389 & 193 & 1 & .193 & الجنس * العمر \\
\hline & & 139 & 396 & 54.963 & الخطأ \\
\hline & & & 400 & 696.488 & الدجموع \\
\hline
\end{tabular}

يتضح من الجدول (15) وجود فروق دالة إحصائيا عند مستوى الدلالة (2 0.05$)$ في الدرجة الكلية للتنمر الإلكتروني (الضحية) تعزى لجنس المفحوص، ولصالح الذكور، فيما أنشارت النتائج إلى عدم وجود فروق ذات دلالة إحصائية في الدرجة الكلية لـقياس التتمر الإلكتروني (الضحية) تعزى للعمر ، وللتفاعل بين الجنس و العمر. 
من الممكن تفسير هذه النتيجة بالرجوع إلى أن المجتمع الأردني المحافظ والذي يعد أحد المجتمعات الشرقية الذي يمتاز بأنه مجتمع ذكوري، يسمح للذكور بالوجود على مو اقع التو اصل الاجتماعي بحرية أكبر وهو ما يجعلهم أكثر عرضة للتنمر الإلكتروني، وربما بالنظر إلى النتيجة السابقة باعتبار الذكور أكثر ممارسة لسلوك التنمر يجعهم أكثر عرضة أيضا للوقوع كضحية، سواء كان رد فعل من الأشخاص الذين تنمروا عليهم أو بالنظر إلى أن قيامهم بسلوك التنمر ما هو إلا رد فحل لكونهم ضحايا سابقين للتنمر الإلكتروني كنوع من

الانتقام و الثار .

التوصيات:

1. التنمر الإلكتروني كسلوك سلبي يستحق الدراسة والبحث في العو امل المؤثرة فيه؛ سعيا للحد منه وحماية المجتمع من آثاره. 2. إيلاء الذكور و الابن الأخير وفقا لترتيبه الميلادي المزيد من الرعاية والمر اقبة لحمايتهم من التنمر الإلكتروني. المقترحات:

1. نشر المقالات التوعوية التي من شأنها التعريف بسلوك التنمر الإلكتروني على نطاق واسع موضحة آثاره النفسية والاجتماعية بين فئات المجتمع على اختلافها. 2. إقامة ندوات ثقافية وبر امج تلفزيونية تستهدف فئات المجتمع كافة؛ للتركيز على ظاهرة التنمر الإلكتروني. 3. اهتمام قسم الإرشاد النفسي في المؤسسات التعليمية بضحايا التنمر الإلكتروني ومساعدتهر على تجاوز آثاره النفسية. 
البوسعيدي، أميمة. (2019). القدرة التنبؤية للذكاء الأخلاقي وأنماط التعلق والمناخ المدرسي في سلوك التبؤ لاى الحلقة الثانية من

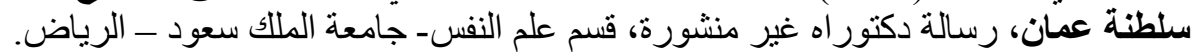

البهاص، سيد أحمد. (2012)، الأمن النفسي لدى الضحايا المتنمرين و أقر انهم ضحايا التنمر المدرسي (در استة سيكومثرية إكلينيكية). مجلة كلية التربية بنها، (92)، 349-395.

الحمداني، عبد المحسن.(2012). سلوك التنمر لاى الأطفال والمراهقين وعلاقته بالعمر والجنس والترتيب الولادي، رسالة ماجستير غير منشورة، جامعة بغداد، العراق.

العباسي، غسق. (2016). سلوك التنمر لادى تلاميذ المرحلة الابتدائية وطلبة المرحلة المتوسطة و علاقته بالجنس و الترتيب الولادي. مجلة

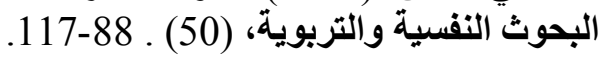

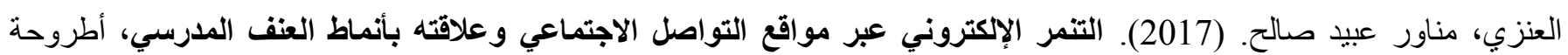

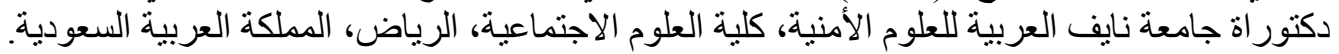

شراب، عبداله؛ شراب، سما .(2019). المناخ الأسري كمتغير وسيط بين العنف الإلكتروني والأمن النفسي لإى الفئة العمرية 14-

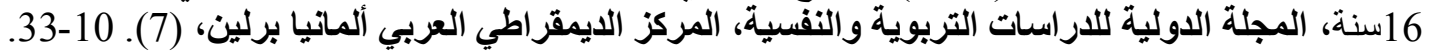

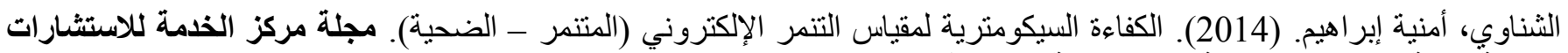

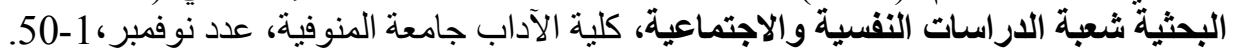

الصبحين، علي و القضاة، محمد. (2013). سلوك التنمر عند الأطفال والمراهقين (مفهومهــ أسبابهـ علاجه)، (ط1)، مطبعة جامعة نايف العربية للعلوم الأمنية، الرياض، المملكة العربية السعودية. قطامي، نايفة والصر ايرة، منى. (2009). الطقل المتنمر. دار المسيرة للنشر و التوزيع، عمان، الأردن.

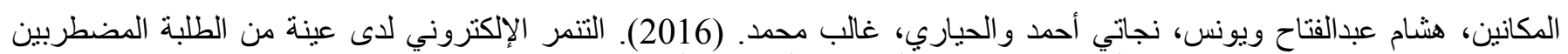

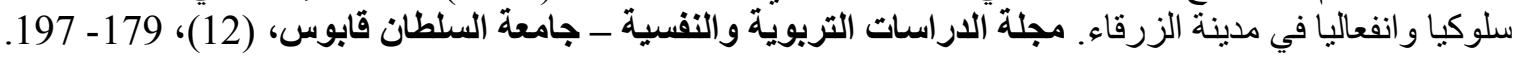
كفينة، أية صبحي (2019). القدرة التنبوئة لعوامل الثخصية الخمس الكبرى والأكاء الانفعالي في التنمر الإكتروني لاى طلبة

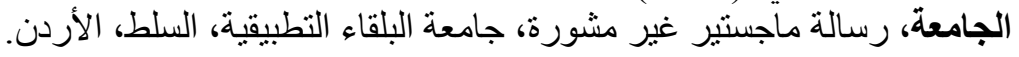

Adler A. (1964). In: Problems of Neurosis: A Book of Case Histories. Mairet P, editor. New York, NY: Harper \& Row, Publishers, Incorporated.

Al Qudah, M.F., Al-Barashdi, H.S., Hassan, E.M.A.H. et al. Psychological Security, Psychological Loneliness, and Age as the Predictors of Cyber-Bullying Among University Students. Community Mental Health J 56, 393-403 (2020). https://doi.org/10.1007/s10597-019-00455-z

Autry, A. L. (2016). The Role of Loneliness and Resilience in Psychosocial Health for Victims of Cyberbullying in a College Population (Doctoral dissertation, University of Mississippi.

Baker, O. E., Tanrikulu, I. (2010). Psychological consequences of cyber bullying experiences among Turkish secondary school children. Procedia Social and Behavioral Sciences, 2, 2771-2776.

Barlett, C. (2015). A meta-analysis of sex differences in cyber-bullying behavior: The moderating role of age. Aggressive Behavior, 40 (5), 474-488.

Buffy, F \& Dianne, O. (2009). Cyberbullying: A literature Review. Paper presented at the Annual Meeting of the Louisiana Education Research Association Lafayette.

Finn, J. (2004). A survey of online harassment at a university campus, Journal of Interpersonal Violence, 19 (4), 468-483.

Floros, G. D., Siomos, K. E., Fisoun, V., Dafouli, E., \& Geroukalis, D. (2013). Adolescent online cyberbullying in Greece: The impact of parental online security practices, bonding, and online impulsiveness. Journal of School Health, 83 (6), 445-453. https://doi.org/10.1111/josh.12049 
Herrera, N. C., Zajonc, R. B., Wieczorkowska, G., \& Cichomski, B. (2003). Beliefs about birth rank and their reflection in reality. Journal of Personality and Social Psychology, 85 (1), 142-150.

Hinduja, S., \& Patchin, J. W. (2008). Cyberbullying: An exploratory analysis of factors related to offending and victimization. Deviant Behavior, 29 (2), 129-156. https://doi.org/10.1080/01639620701457816.

Lee, J. (2017). Traditional Bullying and Cyberbullying in Childhood and Young Adulthood: Prevalence, Relationship, and Psychological Distress Outcomes Among Young Adults (Doctoral dissertation, The Florida State University).

Lee, S. (2010). Cyber-bullying a growing problem in city, China Daily. Retrieved from http://www.chinadaily.com.cn/hkedition/2010-02/06/content_9437534.htm.

MacDonald, C. D., \& Roberts-Pittman, B. (2010). Cyberbullying among college students: Prevalence and demographic differences. Procedia-Social and Behavioral Sciences, 9, 2003-2009. https://doi.org/10.1016/j.sbspro.2010.12.436

Robson, C., \& Witenberg, R. T. (2013). The influence of moral disengagement, morally based selfesteem, age, and gender on traditional bullying and cyberbullying. Journal of school violence, 12 (2), 211-231. https://doi.org/10.1080/15388220.2012.762921.

Ryan, B. (2014). Do perceptions of cyber bullying change with age and gender? A study of college age students (Unpublished Doctoral Dissertation), Walden University, Minneapolis, MN.

Tokunaga, R. S. (2010). Following you home from school: A critical review and synthesis of research on cyberbullying victimization. Computers in Human Behavior, 26, 277-287.

Wong, D., Chan, H., \& Cheng, C. (2014). Cyberbullying perpetration and victimization among adolescents in Hong Kong. Children and Youth Services Review, 36(2014), 133-140. https://doi.org/10.1016/j. childyouth.2013.11.006.

Xiao B. S., \& Wong Y. M. (2013). Cyber-bullying among university students: An Empirical investigation from the social cognitive perspective. International Journal of Business and Information, 8 (1), 34-69.

Zhou, Z., Tang, H., Tian, Y., Wei, H., Zhang, F., \& Morrison, C. M. (2013). Cyberbullying and its risk factors among Chinese high school students. School Psychology International, 34 (6), 630-647.

Zych, I., Catalán, M., Ruiz, R. \& Llorent, V. (2017). Social and emotional competencies in adolescents involved in different bullying and cyberbullying roles. Revista de Psicodidáctica (English ed.). 23 (2), 86-93.

Tantawi, Sayed Mohammed Sayed (2021): The effectiveness of a training program using communicative theory in developing some concepts of Web 3 for educational technology specialists

,Arid International Journal of Educational and Psychological Sciences, VOL.2 NO.3, January(pp. 69-97). 